\title{
NILAI BUDAYA DAN FEMINISME DALAM KUMPULAN CERPEN JERAMBA-JERAMBA MALAM: 10 CERPEN TERBAIK SAYEMBARA MENULIS CERPEN LOKALITAS LUBUKLINGGAU KARYA MIMI LA ROSE, DKK.
}

\author{
Tri Astuti ${ }^{1} \&$ Umiati $^{2}$ \\ 1,2Program Studi Pendidikan Bahasa dan Sastra Indonesia, STKIP PGRI Lubuklinggau \\ JIn. Mayor Toha Kelurahan Air Kuti, Telp 0733-451432, Kota Lubuklinggau, Indonesia \\ Email: astutitri7@gmail.com,umiati@yahoo.co.id
}

\begin{abstract}
Abstrak
Tujuan penelitian ini adalah untuk mendeskripsikan nilai-nilai budaya dan feminisme dalam kumpulan cerita pendek Jeramba-Jeramba Malam karya Mimi La Rose dkk. Dalam kumpulan cerpen tersebut banyak mengangkat nilai-nilai budaya lokalitas Kota Lubuklinggau yang digambarkan melalui tokoh perempuan. Jenis penelitian termasuk penelitian deskriptif kualitatif dengan metode content analysis. Teknik pengumpulan data menggunakan teknik dokumentasi. Data dianalisis berdasarkan konsep teknik interaktif meliputi reduksi data, penyajian data dan penarikan simpulan. Hasil analisis data dapat disimpulkan bahwa pergeseran nilai-nilai budaya di masyarakat berpengaruh terhadap pandangan dan citra perempuan. Pandangan dunia perempuan yang dominan dalam kumpulan cerpen Jeramba-Jeramba Malam adalah campuran dunia domestik dan publik, dunia domestik, dan dunia publik. Perbedaan pandangan ini melahirkan citra positif perempuan, seperti mandiri, lembut, sabar, bertanggung jawab, tabah, kuat, dan tegar. Juga citra negatif perempuan, seperti masa bodoh, tidak setia, dan kurang bertanggung jawab.
\end{abstract}

Kata kunci: nilai budaya, nilai feminisme, dan cerpen

\section{CULTURE VALUES AND FEMINISM IN JERAMBA-JERAMBA MALAM: 10 CERPEN TERBAIK SAYEMBARA MENULIS CERPEN LOKALITAS LUBUKLINGGAU SHORT STORY COLLECTION THE WORK OF MIMI LA ROSE, ET AL.}

\begin{abstract}
The objective of this research was to describe culture values and feminism in a collection of short stories Jeramba-Jeramba Malam by Mimi La Rose et al. This stories explored the cultural values of the Lubuklinggau City locality depicted through female characters. This research was descriptive qualitative research with content analysis method. Data collection techniques using documentation techniques. The data was analyzed based on interactive engineering concepts including data reduction, data presentation, and conclusion drawing. The results of data analysis can be concluded that the shift of cultural values in the society affects the views and image of women. The dominant worldview of women in the collection of short stories of Jeramba-Jeramba Malam is a mixture of the domestic and public world, the domestic world, and the public world. This divergence of views creates a positive image of women, such as independent, gentle, patient, responsible, steadfast, strong, and tough. Also the negative image of women, such as ignorance, unfaithfulness, and lack of responsibility.
\end{abstract}

Keywords: culture values, feminism values, and short story 


\section{A. Pendahuluan}

Dalam penciptaannya, karya sastra tidak dapat dipisahkan dari kehidupan manusia dan budaya suatu bangsa. Interaksi kehidupan dan budaya yang terjadi di suatu negeri tidak terlepas dari kajian sastra. Sebagaimana yang diungkapkan oleh Wicaksono (2014:1) bahwa sastra adalam hasil dari seni kreatif yang objeknya berupa manusia dan kehidupan dengan menggunakan bahasa sebagai mendianya. Dijelaskan juga oleh Kosasih (2012:2), bahwa dalam setiap karya sastra tidak dapat tercipta tanpa melibatkan beberapa unsur kebudayaan. Semua karya sastra akan terikat dan melibatkan dinamika suatu kehidupan masyarakat, yang punya adat dan tradisi tertentu.

Sastra sebagai salah satu dari berbagai bentuk representasi budaya, di dalamnya juga menggambarkan relasi dan rutinitas gender. Perbedaan gender telah melahirkan perbedaan peran sosial di masyarakat. Sering perbedaan peran sosial tersebut dibakukan oleh masyarakat, sehingga tidak ada kesempatan bagi perempuan atau laki-laki untuk berganti peran (Fayumi dkk., 2001:58). Padahal pada hakikatnya, laki-laki dan perempuan merupakan makhluk Tuhan yang berasal dari jenis manusia yang sama. Tidak ada superioritas di antara keduanya, hanya saja ada beberapa perbedaan yang spesifik antara lali-laki dan perempuan, yaitu dari segi fisik dan biologisnya.

Diskursus mengenai ketimpangan gender di kalangan masyarakat masih merupakan isu hangat yang tidak pernah reda hingga saat ini. Paradigma budaya patriarki yang masih berkembang di masyarakat selalu memberikan pandangan yang banyak merugikan perempuan. Perempuan merupakan citra yang sangat menarik untuk dikaji, keberadaannya di antara kutub tradisi dan modernisasi. Di sisi lain, perempuan dianggap sebagai sosok yang mempunyai dua sisi, yaitu keindahan dan kelemahan. Keindahan perempuan menjadi pesona yang dapat membuat laki-laki tergila-gila. Sementara, kelemahannya sering dijadikan alasan laki-laki untuk mengeksplorasi keindahannya, sehingga terjadinya tindak kekerasan, baik fisik, seksual, maupun psikologis. Oleh karena itu, kritik sastra feminisme membantu membangun studi gender yang dipresentasikan dalam sastra (Goldman, 2001:2). 
Kritik sastra feminisme merupakan studi sastra yang difokuskan pada analisis terhadap peran dan fungsi perempuan dalam masyarakat (Sugihastuti \& Suharto, 2015:18). Feminisme merupakan suatu pemikiran dan gerakan yang berangkat dari kesadaran perempuan untuk memperjuangkan kaumnya dari belenggu gender yang bersumber dari budaya patriarki. Feminisme tidak menuntut perlakuan yang istimewa terhadap perempuan. Feminisme hanya menuntut kesetaraan maupun kesempatan yang sama antara laki-laki dan perempuan dalam berbagai bidang demi kemajuan bersama. Sebagaimana diungkap oleh Syuropati dan Soebahman (dalam Suaka, 2014:126)

"Pada dasarnya gerakan feminisme ini muncul karena adanya dorongan ingin menyetarakan
hak antara laki-laki dan perempuan yang selama ini seolah-olah perempuan tidak dihargai
dalam pengambilan kesempatan dan keputusan dalam hidup. Perempuan merasa terkekang
karena superioritas laki-laki dan perempuan hanya dianggap sebagai 'bumbu penyedap'
dalam hidup laki-laki. Adanya pemikiran tersebut, tampaknya sudah membudaya sehingga
perempuan harus berjuang keras untuk menunjukkan eksistensi dirinya di mata dunia."

Jeramba-Jeramba Malam merupakan kumpulan sepuluh cerita pendek (cerpen) pemenang sayembara nasional tentang lokalitas kota Lubuklinggau yang diselenggarakan oleh penerbit Bennyinstitude bekerja sama dengan Dewan Kesenian Kota Lubuklinggau. Dalam kumpulan cerpen Jeramba-jeramba Malam tersebut banyak mengangkat nilai-nilai budaya lokal Kota Lubuklinggau. Penggambaran tokoh dan karakter yang dilukiskannya banyak melalui peran tokoh perempuan. Inilah yang menjadi dasar landasan analisis penulis tentang nilai budaya dan feminisme dalam cerpen Jeramba-Jeramba Malam karya Mimi La Rose dkk.

Konsep analisis nilai budaya, penulis merujuk pada teori Kluchohn (dalam Setiadi, dkk. 2010:31), bahwa nilai budaya meliputi: 1) hakikat hidup manusia, 2) hakikat karya manusia, 3) hakikat kedudukan manusia dalam ruang dan waktu, 4) hakikat hubungan manusia dengan alam, dan 5) hakikat hubungan antarmanusia. Sementera konsep analisis feminisme, penulis merujuk pada konsep Endraswara (2013:146) yang menyatakan bahwa penelitian feminisme dapat memfokuskan pada tiga kajian yaitu, (1) kedudukan dan peran tokoh perempuan dalam karya sastra; (2) ketertinggalan kaum perempuan dalam segala aspek kehidupan, termasuk pendidikan dan aktivitas kemasyarakatan; dan (3) memperhatikan 
pembaca sastra, khususnya bagaimana tanggapan pembaca terhadap emansipasi wanita dalam sastra.

Dalam mengungkap ketiga fokus kajian feminisme di atas, penulis menggunakan lima pencitraan nilai perempuan yang dapat dilihat dalam karya sastra menurut Sihaloholistick (21 Juli 2014), meliputi citra pigura, citra pilar, citra peraduan, citra pinggan, dan citra pergaulan. Hasil kajian ini akan memperlihatkan bagaimana peran dan kedudukan perempuan dalam keluarga, masyarakat, dan dunia aktivitas yang digelutinya. Sebagaimana diungkap oleh Endaswara (2013:146) bahwa kajian feminisme akan tercapai dengan sukses apabila peneliti feminisme sastra dapat memanfaatkan kajian kualitatif dengan mendeskripsikan data-data kualitatif, misalnya mendeskripsikan status dan peran perempuan dalam keluarga, masyarakat, dan lingkungan pekerjaannya. Data-data ini harus dibahas secara proporsional menggunakan sudut pandang perempuan, bukan sudut pandang laki-laki melihat perempuan. Dengan kata lain, didasarkan pada latar kehidupan perempuan, yang meliputi latar kehidupan domestik, juga latar kehidupan domestik, dan publik.

Hasil penelitian relevan terkait dengan penelitian ini adalah penelitian yang dilaksanakan oleh Noermanzah (2017) dengan judul Plot in a Collection of Short Stories "Sakinah Bersamamu" Written by Asma Nadia with Feminimism Analysis. Hasil penelitian ini menunjukkan bahwa plot dalam kumpulan cerpen Sakinah Bersamamu karya Asma Nadia, secara umum memilik dua bentuk yaitu berbentuk plot maju dan berbentuk plot mundur, dengan tahapan dimulai dengan pengenalan sederhana, konflik, pengenalan penyebab konflik, komplikasi, peleraian, dan penyelesaian. Bentuk konflik dalam kumpulan cerpen berupa konflik batin dan penyelesaiannya berbentuk tertutup dan terbuka. Plot yang dihadirkan oleh Asma Nadia dalam kumpulan cerpen Sakinah Bersamamu mampu menghadirkan peristiwa demi peristiwa tentang permasalahan dalam rumah tangga, mulai dari permasalahan dalam kehidupan sosial, permasalahan dari dalam keluarga terutama suami, dan permasalahan dari masa lalu.

Dari hasil penelitian relevan ini, kajian tentang feminisme dan nilai budaya masih menjadi hal yang menarik untuk diteliti karena bermanfaat dalam pengembangan karya sastra di Indonesia dan menjadi salah satu bahan ajar 
sastra yang dapat diajarkan di tingkat sekolah dasar. Selain itu, dengan mengangkat nilai feminisme memberikan warna baru tentang karya sastra sebagai cerminan dalam perkembangan kebudayaan khususnya budaya perempuan dalam rumah tangga dan masyarakat.

\section{B. Metode Penelitian}

Jenis penelitian ini termasuk penelitian deskriptif kualitatif dengan metode content analysis. Apabila ditinjau dari paradigmanya, penelitian ini termasuk ke dalam studi kepustakaan dan memiliki karakteristik sebagaimana dicirikan oleh rancangan kualitatif. Oleh sebab itu, data yang diperlukan berupa kata-kata dan bukan angka-angka (Aminudin, 2010:16). Sumber data berupa kumpulan cerpen Jeramba-Jeramba Malam yang terdiri dari sepuluh cerpen pemenang sayembara nasional tentang lokalitas Lubuklinggau yang ditulis oleh Mimi Larose dkk. Sepuluh judul cerpen yang ada dalam kumpulan cerpen lokalitas Lubuklinggau tersebut, sebagai berikut:

Tabel 1. Data Kumpulan Cerpen Jeramba-Jeramba Malam Karya Mimi Larose dkk.

\begin{tabular}{clll}
\hline No. & \multicolumn{1}{c}{ Judul cerpen } & \multicolumn{1}{c}{ Karya } & \multicolumn{1}{c}{ Keterangan } \\
\hline 1. & Jeramba-Jeramba Malam (JJM) & Mimi La Rose & Juara 1 \\
\hline 2. & $\begin{array}{l}\text { Kota yang Dibangun dari dalam Air } \\
\text { (KDDA) }\end{array}$ & $\begin{array}{l}\text { Alexander Robert } \\
\text { Nainggolan }\end{array}$ & Juara 2 \\
\hline 3. & Menyambut Dumarana (MD) & Awal Akar & Juara 3 \\
\hline 4. & $\begin{array}{l}\text { Hari Kematian Dayang Dungu } \\
\text { (HKDD) }\end{array}$ & Muawiyatu Al Laitsi & - \\
\hline 5. & $\begin{array}{l}\text { Sebelum Pesta Pernikahan Salah } \\
\text { Satu Cucu Nenek Nahadim (SPSCN) }\end{array}$ & Majenis Panggar Besi & - \\
\hline 6. & Secantik Peri (SP) & Robi Effendi & - \\
\hline S. & Humai: Rengget Dehe (HRD) & Della Naradika & - \\
\hline 8. & $\begin{array}{l}\text { Tauladan Patah Hati yang Menulis } \\
\text { Kitab (TPHMK) }\end{array}$ & B.E. Raynangge & - \\
\hline 9. & $\begin{array}{l}\text { Yang Hilang dan yang Kembali } \\
\text { (YHYK) }\end{array}$ & Wendy Fermana & - \\
\hline 10. & Cunguk Ngibon (CN) & Misti Kurnia & \\
\hline
\end{tabular}

Untuk teknik analisis data penelitiannya, penulis merujuk pada teknik interaktif yang dikemukakan oleh Milles \& Huberman (2007), yaitu dengan langkah-langkah analisis di mulai dari kegiatan reduksi data, penyajian data, interpretasi data, dan penarikan simpulan. 


\section{Hasil Penelitian dan Pembahasan}

\section{Hasil Penelitian}

Jeramba-jeramba Malam karya Mimi La Rose dkk. merupakan kumpulan sepuluh cerpen terbaik hasil sayembara menulis cerpen lokalitas Lubuklinggau. Dalam kumpulan cerpen tersebut banyak mengangkat nilai-nilai budaya lokalitas kota Lubuklinggau yang terimplementasi melalui tokoh-tokoh perempuan. Dari hasil analisis data nilai budaya diperoleh nilai-nilai budaya yang terkandung dalam kumpulan cerpen JJM, sebagai berikut.

Tabel 2. Nilai-nilai Budaya dalam Kumpulan Cerpen Jeramba-Jeramba Malam

\begin{tabular}{|c|c|c|}
\hline No. & Sistem Nilai Budaya & Bentuk Nilai Budaya \\
\hline 1. & Nilai Hakikat Hidup Manusia & $\begin{array}{l}\text { Keyakinan terhadap takdir, keyakinan } \\
\text { pada hal gaib, dan kepercayaan pada } \\
\text { mitos }\end{array}$ \\
\hline 2. & Nilai Hakikat Karya Manusia & $\begin{array}{l}\text { Kreatif, sabar, patuh, semangat, } \\
\text { pekerja keras, dan tangguh. }\end{array}$ \\
\hline 3. & $\begin{array}{l}\text { Nilai hakikat manusia dalam ruang } \\
\text { dan waktu }\end{array}$ & $\begin{array}{l}\text { Pemanfaatan waktu manusia } \\
\text { berorientasi pada masa lampau dan } \\
\text { masa kini atau masa yang akan datang. } \\
\text { Orientasi waktu menggambarkan } \\
\text { pengubahan perkembangan fisik dan } \\
\text { pola pikir menjadi lebih maju. }\end{array}$ \\
\hline 4. & $\begin{array}{l}\text { Nilai hakikat hubungan manusia } \\
\text { dengan alam }\end{array}$ & $\begin{array}{l}\text { Pemanfaatan kenampakan alam, } \\
\text { pemanfaatan benda-benda alam. }\end{array}$ \\
\hline 5. & $\begin{array}{l}\text { Nilai hakikatHubungan manusia } \\
\text { dengan sesamanya }\end{array}$ & $\begin{array}{l}\text { Kasih sayang, tolong-menolong, } \\
\text { hubungan kekeluargaan, dan kesetiaan }\end{array}$ \\
\hline
\end{tabular}

Sedangkan analisis feminisme mendapatkan nilai-nilai peran dan kedudukan perempuan dalam lima pencitraan nilai perempuan sebagai berikut.

Tabel 3. Nilai-Nilai Feminisme dalam Kumpulan Cerpen Jeramba-Jeramba Malam

\begin{tabular}{lll}
\hline No. Pencitraan Nilai Perempuan & \multicolumn{1}{c}{ Bentuk Pencitraan Nilai Perempuan } \\
\hline \multirow{3}{*}{$\begin{array}{l}\text { Perempuan menjadi simbul status dan kedudukan } \\
\text { laki-laki. Perempuan harus memikat, menonjolkan }\end{array}$} \\
ciri fisik dan biologis, sehingga peempuan harus \\
cantik dan menarik. Sekalipun tak jarang, \\
kecantikan dan kemerikannya justru menjadi \\
problema dalam kehidupannya.
\end{tabular}

Silampari Bisa: Jurnal Penelitian Pendidikan Bahasa Indonesia, Daerah, dan Asing Vol. 1, No. 1, 2018 


\begin{tabular}{lll}
\hline 3. Citra Peraduan & $\begin{array}{l}\text { Perempuan menjadi obyek seks laki-laki, } \\
\text { sehingga keindahan perempuan menjadi } \\
\text { problema dalam kehidupannya. }\end{array}$ \\
\hline 4. Citra Pinggan & $\begin{array}{l}\text { Citra positif perempuan; lembut, penyayang, } \\
\text { sabar, ikhlas, tegar, tanggung jawab, dan mandiri. } \\
\text { Citra negatif perempuan: bersikap masa bodoh, } \\
\text { dan kurang bertanggung jawab pada keluarga. }\end{array}$ \\
\hline 5. Citra Pergaulan & $\begin{array}{l}\text { Menjadi perempuan mandiri, tidak setia, dan } \\
\text { mengabaikan nilai keperempuannya }\end{array}$ \\
\hline
\end{tabular}

\section{Pembahasan}

Jeramba-Jeramba Malam yang selanjutnya disingkat JJM, sebuah judul dari kumpulan cerpen yang benar-benar menggambarkan dan mewakili keseluruhan isi cerita. Istilah jeramba, dalam masyarakat Kota Lubuklinggau dan Kabupaten Musi Rawas diartikan sebagai jembatan, merupakan perantara atau penghubung dari tempat yang satu ke tempat yang lain. Sedangkan malam dalam Kamus Besar Bahasa Indonesia (Badan Pengembangan dan Pembinaan Bahasa, 2017) adalah waktu setelah matahari terbenam hingga matahari terbit atau kelam atau gelap. Pada saat malam tiba, kita tentu akan merasakan hal yang membuat perasaan kita berbeda. Mungkin identik dengan rasa takut ataupun khawatir, tetapi terkadang malam menampakkan diri sebagai tempat yang seolah menjadi milik kita sendiri dan tidak ingin kita lepaskan (begitu sunyi, tentram, damai, nyaman, dan begitu indah). Sebagaimana dalam kumpulan cerpen JerambaJeramba Malam. Muatan isi yang disampaikan dalam JJM menjadi jembatan penghubung kita untuk mencoba memahami sesuatu yang tidak kita ketahui dan sering sengaja kita lupakan. Seperti yang dikatakan Mimi La Rose di akhir ceritanya:

"Jeramba ini membuka matamu, membuka hatimu yang nyaris tertutup."

(JJM, hal. 16)

Dalam kumpulan cerpen JJM ini, banyak nilai-nilai sosial-kultural, nilai moral, nilai feminisme, dan nilai-nilai yang lain yang bernuansa keraifan lokal Kota Lubuklinggau yang bisa kita petik. Nilai-nilai ini yang nyaris tergerus oleh budaya pragmatik hedonis barat, sehingga banyak ditemukan anak-anak negeri yang rela menjadi 'jongos' di rumahnya sendiri (Zuhdi, 2017). Dalam analisis dan pembahasan data, sesuai dengan judul penelitian, maka gambaran nilai budaya 
hanya akan diambil dari gambaran tokoh dan penokohan perempuan yang ada dalam cerpen. Gambaran nilai budaya tersebut akan dikombinasikan dalam kajian analisis feminisme.

Nilai budaya yang pertama, yaitu hakikat hidup manusia. Secara filosofis hakikat hidup manusia merupakan kesatuan integral dari potensi-potensi esensial yang ada pada diri manusia. Perbedaan pandangan mengenai hakikat hidup, akan menghasilkan berbagai perilaku yang berbeda dalam menyikapinya. Dalam kumpulan cerpen JJM tergambar nilai hakikat hidup manusia, meliputi keyakinan terhadap ketentuan takdir, keyakinan pada hal ghaib, dan kepercayaan pada mitos. Takdir adalah segala sesuatu atau ketentuan yang pasti dan akan terjadi pada kita. Secara umum, orang beranggapan bahwa takdir dan nasib memiliki arti yang sama, bahkan dalam bahasa Inggris pun takdir dan nasib diterjemahkan sebagai 'destiny fate' yang artinya mengarah kepada 'segala sesuatunya sudah ditentukan dari atas (yaitu Tuhan) dan manusia tidak ada andil/kehendak bebas untuk mengubahnya'. Bagi seorang Muslim, tentu membedakan antara takdir dan nasib. Nasib itu bisa diubah, namun takdir adalah ketentuan dari Tuhan.

Dalam kumpulan cerpen JJM keyakinan terhadap takdir tergambar dalam kutipan tokoh perempuan "Kau" dalam cerpen JJM, yang harus mengabdikan hidupnya pada kedua orang tuanya karena ia menyadari takdirnya sebagai anak tunggal.

"Bukan tak mau, tapi keluargamu, orang tuamu butuh dirimu dan ambisimu tak cukup kejam sehingga membuatmu tega menitipkan orang tuamu di panti jompo. Tidak kau bukan anak durhaka. Kau terlahir sebagai anak tunggal, dan hanya itu yang kau sesali." (JJM, hal 16)

Selanjutnya juga dalam kutipan dialog tokoh "Bunda" pada kumpulan Cerpen JJM pada judul cerpen SP ketika nenek menyuruh "Bunda" menghajar wanita selingkuhan suaminya.

"... mugkin Bunda bukan orang yang pantas dan belum melakukan yang terbaik sebagai seorang istri."(SP: 53)

Kayakinan menerima takdir ini melahirkan sikap kepasrahan, ketegaran, dan kesabaran. Sikap ini mengidentikan dengan citra positif perempuan. Citra nilai perempuan yang tergambar dalam kutipan di atas adalah lukisan citra pinggan, yaitu citra perempuan yang tidak bisa melepaskan diri dari kodrat peran dan 
kedudukannya dalam keluarga, yaitu sebagai penanggung jawab kehidupan rumah tangga. Manakala ia merasa tidak dapat memenuhi kodratnya sebagai perempuan, perempuan yang benar-benar menyadari kodrat nilai citra pinggan, ia akan memilih menjalani hidup dengan ikhlas, sabar, dan berusaha untuk tegar. Sikap ini yang biasa dimanfaatkan oleh 'laki-laki' yang berpandangan tradisional, memandang perempuan sebagai objek domestik, sehingga pada akhirnya bertindak semena-mena. Seperti tergambar dalam kutipan berikut.

"Bunda juga janda atau dengan sadar menjandakan dirinya. Sengaja membiarkan ayah tidak pulang lagi ke rumah. Ketika kutanya perihal Ayah yang menghilang, nenek hanya menjawab jika ayah dibawa peri terbang ke langit" (SP, hal. 52)

Sebaliknya, perempuan yang tidak memahami dan menghayati nilai perempuan sebagai citra pinggan, ia akan melakukan perlawanan dan bersikap masa bodoh terhadap tanggung jawab peran dan kedudukannya dalam keluarga. Sikap ini mengidentikkan dengan citra negatif perempuan. Lihat dalam kutipan berikut.

"Berhentilah bertanya, pacak-pacaklah kamu nak nyari duet di mano," kata lbu saya yang kesehariannya tidak jelas. Kadang ia di rumah, di pasar, belanja, memasak, lalu ke pasar lagi, mencuci, lalu ... entahlah ....”. (CN,, hal. 94-95)

Keyakinan pada hal yang gaib, juga mitos merupakan nilai budaya yang ditemukan dalam nilai hakikat hidup manusia.

"...Lalu ia teringat tentang muasal sebuah kota. Sejarah yang dipenuhi dengan kemustahilan. Kota yang dipenuhi dengan mitos." (KDDA, hal 17)

"Saat menari, aku bisa merasakan aura peri, yang menurut Mrs. Emilia ada dalam diriku, aku merasakan energi yang begitu hebat ada dalam diriku ...." (SP, hal. 55)

" 'Humei'. Semua warga reflek menoleh pada wanita paruh baya itu. Seketika ume berselimut hening. Mereka teringat mitos yang begitu pekat perihal humei ....". (HRD, hal 63)

Mitos tentang 'Peri' dan 'Humei” dalam kumpulan cerpen JJM digambarkan dengan perempuan yang cantik untuk 'Peri' dan buruk rupa untuk 'Humai'. Hal ini merupakan gambaran nilai perempuan dalam citra pigura. Dalam citra pigura, perempuan digambarkan sebagai makhluk yang harus memikat. Untuk itu, ia harus menonjolkan ciri fisik dan biologis. Perempuan menjadi simbol status dan kedudukan laki-laki. Perempuan dalam citra pigura akan melakukan apapun untuk memperindah dan membuat dirinya memikat. Isu 'natural anomy" bahwa umur perempuan, ketuaan perempuan akan menjadi momok yang menghantui para 
perempuan. Kesedihan berlebihan akan dirasai perempuan, apabila ia tidak dianggap cantik atau paling cantik lagi yang dirasai Zaza dalam cerpen SP).

Kondisi seperti ini akan dimanfaatkan oleh laki-laki 'yang berhati jahat' untuk mengeksploitasi perempuan, sehingga perselingkuhan pun akan sering terjadi, perempuan akan menjadi kaum yang lemah dan dianggap tidak berdaya. Citra ini akan berkaitan dengan citra peraduan yang memberikan gambaran bahwa perempuan akan menjadi objek pemuasan laki-laki, terutama pemuasan seksual, sehingga kecantikan perempuan ujungnya justru akan mencelakai dirinya. Ini digambarkan dalam mitos terjadinya Kota Lubuklinggau dalam cerpen KDDA, ketika Linggau saudara laki-laki Dayang Torek harus melindungi saudara perempuannya dengan menyembunyikan Dayang Torek di dasar lubuk sungai yang paling dalam.

“... Hingga engkau tahu, jika jalanan sepanjang kotamu akan terus berembun, karena air mata asmara. Dayang Torek pun menangis karena memang tak ada lelaki yang benar-benar bersanding menikahi dengannya”. (KDDA, hal. 20-21)

Nilai budaya yang kedua yaitu hakikat karya manusia. Dalam menjalani kehidupan ini, manusia mempunyai dua kepentingan yang berbeda, yaitu kepentingan individu dan kepentingan umum (sosial). Untuk memenuhi kepetingan ini, manusia harus beraktivitas dan berkarya. Nilai-nilai hakikat karya manusia yang ditemukan dalam kumpulan cerpen JJM meliputi: nilai kreatif, sabar, patuh, semangat, pekerja keras, dan tangguh. Gambaran nilai kretif terlukis dalam cerita pembuatan batu giling dalam cerpen JJM sebagai berikut.

"Sebenarnya aku kemari karena dua hal, salah satunya membeli batu giling. Namun, naluri jurnalistikku tergelitik, saat aku melihat langsung proses pembuatannya di Bukit Sulap kemarin. Di kota besar, batu giling yang asli menjadi barang langka, baik dari keaslian dan penggunaannya. Orang-orang sekarang lebih menyukai sesuatu yang instan dan praktis. Kurasa wanita di sampingku ini juga tak bisa menggunakannya," Dia menggodamu. (JJM, hal. 9)

Ya, realita yang harus kita hadapi, sebuah penghargaan terhadap nilai kretivitas seseorang saat ini mulai berkurang.

"Pantas saja pengrajin batu giling hidupnya susah. Pernahkah kau menemukan pekerjaan kasar yang membuat tanganmu lepuh, rusak, dan kebal rasa selain si pencacah batu?" (JJM, hal 9-10)

Pergeseran nilai budaya instan dan praktis meluruhkan nilai perempuan sebagai citra pinggan. 
"Bukankah kita harus mengikuti kemajuan zaman? Sergahmu tak mau kalah. Kau memang tak pandai menggunakan batu giling, selain ribet, tanganmu acapkali kepanasan setiap menyentuh air cabai. Bagimu blender adalah penyelamat kaum hawa." (JJM, hal 9)

Nilai kesabaran, kepatuhan, ketangguhan, semangat, dan gambaran perempuan sebagai pekerja keras terlihat dalam fenomena ketika perempuan memasuki dunia kerja. Fenomena seperti ini yang menyebabkan lahirnya gerakan kaum feminisme. Konsep femenisme secara budaya menyatakan bahwa lakilaki dan perempuan itu sederajat, hanya kodratnya yang berbeda sehingga wilayah kegiatan dan tanggung jawabnya berbeda pula. Hal ini yang membuat cukup kuat gerakan kaum feminisme dalam membuktikan bahwa kegiatan ekonomi sangat berkaitan dengan peran dan kedudukan perempuan dalam rumah tangga atau keluarga. Maka benar-benar perempuan adalah sebagai pengurus utama keluarga. Tuntutan keadilan dan kesamaan hak dalam kehidupan bermasyarakat, tidak bisa terelakkan. Di sisi lain, ada berbagai latar belakang perempuan memasuki pasar kerja. Menurut Sihaloholistik (2014) ada 3 latar belakang perempuan memasuki pasar kerja.

Pertama, untuk memenuhi kebutuhan diri sendiri dan keluarga, terutama bagi perempuan yang belum bersuami, tetapi juga menopang keberlangsungan ekonomi keluarga. Seperti dalam kutipan:

"Memutuskan untuk melajang sampai usia kepala tiga bukan hal mudah untuk perempuan itu. Dia hanya ingin bekerja agar umak tak harus jadi kuli batu lagi...." (HKDD, hal.37)

Kedua, perempuan tidak lagi bersuami, tetapi harus memenuhi kebutuhan anak-anak dan keluarganya. Ini tergambar dalam tokoh Umak pada cerpen HKDD dan Bunda pada cerpen SP. Tokoh Umak bekerja menjadi kuli batu untuk menghidupi anaknya semata wayangnya, sedang Bunda bekerja membuka warung makan di Pasar Mambo. Namun, yang menarik pada dua tokoh ini adalah prinsip hidup wanita pekerja keras yang sederhana, tabah, kuat, dan sabar, serta ikhlas menerima nasib. Berikut ini beberapa kutipan yang mendukung hal tersebut.

Pada tokoh Umak:

“... Umak berkata dia pilih pekerjaan itu karena tak harus berpikir. Hidup pada dasarnya seperti batu bersisi dua, tinggal pilih yang mana, keras atau kuat. Dan Umak pilih kekuatan itu untuk bertahan hidup, bukan kekerasan." (HKDD, hal. 37)

Silampari Bisa: Jurnal Penelitian Pendidikan Bahasa Indonesia, Daerah, dan Asing Vol. 1, No. 1, 2018 
Jangan pernah merasa harus menyesal. Meskipun nasi terlanjur jadi bubur, nasi masih bisa jadi hidangan lezat jika kamu mampu meraciknya. Tetaplah seistimewa tempoyak. Dia punya masa lalu kelam sebagai durian busuk. Tak berguna. Namun pada akhirnya, dia akan punya tempat istimewa di lidah kita." (HKDD, hal. 41)

Pada tokoh Bunda:

"Bunda tidak membuka warung hingga larut malam seperti lapak Bik Sulas, janda yang tinggal di gang ujung pasar. Lebih baik menghindari fitnah, begitu Bunda selalu menjelaskan ....". (SP, hal. 52)

Pencitraan perempuan sebagai citra pilar, digambarkan dengan perempuan sebagai tulang punggung keluarga. Perempuan sederajat dengan laki-laki, namun karena kodratnya berbeda dengan laki-laki, perempuan tidak memiliki kebebasan seperti laki-laki walau ia menjalani tanggung jawabnya lebih luas dari persoalan domestik. Umak dalam menjalani tanggung jawabnya memilih kekuatan untuk bertahan hidup dan bukan kekerasan. Begitu pun Bunda membatasi diri membuka warung tidak sampai larut malam untuk menghindari fitnah.

Ketiga, masih bersuami namun ikut membantu suami dalam memenuhi kebutuhan hidup keluarga dan rumah tangganya. Ini tergambar dalam SPSCN pada tokoh Fatma. Tokoh Fatma adalah cerminan tokoh wanita masa kini yang sudah terpengaruh budaya modernisasi.

"Fatma yang wanita karier, tentu sibuk membagi waktu antara pekerjaan dan rumah tangganya bersama Jaudi." (SPSCN, hal. 45)

Fatma, tokoh yang terjun ke dunia publik. Fatma gambaran perempuan yang memiliki citra pergaulan. Citra ini ditandai dengan pergulatan perempuan untuk masuk ke dalam kelas-kelas tertentu yang lebih tinggi di masyarakat, perempuan dilambangkan sebagai makhluk yang anggun dan menawan. Pencitraan perempuan seperti ini, tidak sekedar dilihat sebagai obyek, namun juga dilihat sebagai subyek pergulatannya dalam menempatkan diri pada realitas sosial. Sekalipun tidak jarang, perempuan lupa bahwa dirinya telah masuk dalam dunia hiperrealistik atau pseudo-realistik.

Sebagian perempuan di dunia publik, tidak akan pernah mampu meninggalkan dunia domestiknya, sehingga hal tersebut sering menimbulkan konflik baru dalam kehidupannya. Perempuan mengemban duble burden atau peran ganda, antara pekerjaan dan rumah tangga. 
"Mungkin kesibukan pulalah yang menyebabkan Fatma mengalami keguguran pada kehamilannya yang pertama dulu." (SPSCN, hal. 45)

"Setelah meninggalnya Wenti, hubungan Fatma dan keluarga Lubuklinggau agak renggang, meski tidak ada selisih paham di antara mereka." (SPSCN, hal. 45)

Nilai budaya yang ketiga yaitu hakikat manusia dalam ruang dan waktu. Manusia sangat terikat oleh ruang dan waktu. Ruang dan waktu terkadang membatasi segala pergerakan manusia. Sebagaimana yang terjadi pada tokoh "Kau" dalam cerpen JJM.

Waktu atau dimensi temporal memiliki dua makna, denotatif dan konotatif. Makna waktu secara denotatif adalah suatu kesatuan, seperti menit, detik, jam, hari, bulan, tahun, dan sebagainya. Sedangkan makna waktu secara konotatif adalah waktu sebagai konsep. Sementara ruang merupakan tempat terjadinya berbagai peristiwa, baik peristiwa alam maupun peristiwa sosial serta peristiwa sejarah dalam proses perjalanan waktu.

Dalam kumpulan cerpen JJM, ada tiga bentuk peristiwa, yaitu peristiwa alam atau peristiwa sejarah digambarkan dalam cerita legenda asal muasal terjadinya Kota Lubuklinggau tergambar dalam cerpen KDDA. Selanjutnya, peristiwa sosial dengan "Mandi Kasai" dalam cerpen TPHMK, sebuah tradisi ritual memandikan sepasang kekasih di sungai yang disaksikan oleh teman dan kerabat menjelang pernikahan. Tradisi ini mempunyai dua makna: Pertama, sebagai pertanda sepasang kekasih calon pengantin akan meninggalkan masa remaja dan memasuki kehidupan berumah tangga; Kedua, membersihkan jiwa dan raga sepasang kekasih yang akan menikah. Kemudian peristiwa sosial yang telah membuka mata dan hati tokoh "Kau" dalam cerpen JJM.

"Jeramba ini membuka matamu, membuka hatimu yang nyaris tertutup" (JJM:16).

Gambaran nilai yang berorientasi pada masa lampau, yang memandang kehidupan masa lampau yang buruk, sehingga tokoh "Kau" menutup mata hatinya untuk melihat sisi lain kehidupan baik dari mantan kekasihnya dan gengnya. Tokoh mantan murid sanggarnya dan mantan kekasihnya telah menyadarkan tokoh "Kau" untuk bisa melihat realita (orientasi masa kini) dan pandangan kehidupan yang lebih luas (orientasi masa depan). 
Nilai budaya yang keempat yaitu hakikat manusia dengan alam. Alam adalah sesuatu yang meski dijaga dan dihargai karena keberadaannya merupakan faktor penting yang mempengaruhi kehidupan manusia. Berkaitan dengan hal tersebut, ada dua pandangan tentang alam. Pertama, beranggapan bahwa alam dapat dilawan dan dikuasai. Terjadilah kecenderungan mengeksploitasi dan mengeksplorasi alam untuk mencapai keinginan dan tujuannya. Akibatnya, muncul berbagai bencana alam dan berbagai penyakit karena kesalahan manusia. Kedua, nilai yang cenderung menyelaraskan diri dengan alam, sehingga masyarakat cenderung melestarikan dan menjaga serta menciptakan keselarasan alam demi kelangsungan hidup masa depan.

Cerpen KDDA, wujud pelestarian alam berupa pelestarian budaya berbentuk legenda tentang sejarah asal mula Kota Lubuklinggau yang penuh kemustahilan dan mitos. Kemustahilan berupa disembunyikannya Dayang Torek di dasar lubuk sungai dan mitos tentang kecantikan Dayang Torek yang sampai saat ini masih tetap diyakini oleh masyarakat Kota Lubuklinggau dan sekitarnya. Selanjutnya, tradisi 'Mandi Kasai' dalam cerpen TPHMK, sebuah ritual adat Lubuklinggau memandikan sepasang kekasih di sungai yang disaksikan oleh teman dan kerabat menjelang pernikahan. Salah satu maknanya adalah membersihkan jiwa dan raga sepasang kekasih yang akan menikah.

Dua peristiwa alam ini menyampaikan makna pesan citra pigura dan citra peraduan terhadap nilai perempuan. Citra pigura, tergambar pada tokoh 'Dayang Torek' tokoh perempuan yang memiliki kelebihan dari sisi keindahan fisik dan biologis. Kelebihan ini ternyata menjadi problema dalam menjalani kehidupannya. Citra peraduan, tergambar dari tradisi ritual 'Mandi Kasai' dalam cerpen TPHMK. Nilai citra ini menonjolkan erotisme perempuan. Perempuan memang diciptakan sebagai obyek seks laki-laki, sehingga budaya patriarki berperan dalam mengkontruksikan citra peraduan. Sering citra ini dijadikan alat oleh 'laki-laki yang kurang baik' untuk menjatuhkan perempuan.

Nilai budaya yang kelima yaitu hakikat hubungan manusia dengan sesama. Hubungan yang terjadi antarsesama manusia disebut dengan hubungan sosial. Dalam kumpulan cerpen JJM terdapat dua sudut pandang hubungan sosial, hubungan sosial masyarakat tradisional dan masyarakat modern. Hubungan 
masyarakat tradisional pada umumnya hidup dalam hubungan sosial yang sangat erat. Hubungan ini berupa masyarakat kekerabatan, kasih sayang, saling menghargai, tanggung jawab, toleransi, dan kesetiaan. Hubungan kekerabatan, kasih sayang, dan rasa tanggung jawab tergambar dalam kutipan berikut.

"Dengan kesaktiannya pula, ditancapkan taringnya yang panjang ke dasar lubuk. Jauh ke dasar yang tak bisa ditempuh retina mata. Disembunyikan.Dayang Torek ke dasar sungai yang dalam. Di sanalah dia tinggal dan menetapsepanjang tahun. Telah diciptakannya pula istana yang megah, jauh di kedalamansungai, melengkapi segala kebutuhan yang diperlukan." (JJM, hal. 21)

Demi rasa kasih kepada saudaranya, karena ketakutan saudaranya dipinang si Pahit Lidah, Linggau menyembunyikan saudaranya 'Dayang Torek' ke dasar lubuk sebuah sungai. Tanpa disadari bahwa justru itu merupakan kesedihan mendalam yang dihadapi Dayang Torek. Karena dengan demikian selamanya tak ada laki-laki yang benar-benar bersanding dan menikah dengannya (JJM, hal 21), pengabaian terhadap citra peraduan 'Dayang Torek'.

Hubungan rasa kasih sayang antarsesama, tergambar dalam kutipan cerpen HKDD berikut.

"Perempuan memang mudah tersentuh. Entah apalagi pasalnya, mereka akhirnya sering bertemu dan bertukar janji manis." (HKDD, hal.38)

Pertemuan antara Dayang Dungu dan Saukani, yang diawali dengan Saukani menolong Dayang ketika sepeda motornya bermasalah, melahirkan rasa kasih yang berkembang menjadi cinta dua anak manusia. Selanjutnya, gambaran hubungan sosial berupa kesetiaan dan keikhlasan tergambar pada tokoh 'Úmak' dalam cerpen HKDD dan tokoh 'Bunda' dalam cerpen SP. Berikut kutipannya:

"Kata Umak, Bapak mati kecelakaan. Kata bibik sebelah rumah, Bapak waktu itu merantau ke Jakarta dan suatu hari pulang dalam kondisi sudah jadi mayat, diantar oleh beberapa orang yang mengaku dari pihak keluarga istri muda di Jakarta". (HKDD, hal. 36)

"Bunda juga janda atau dengan sadar menjandakan dirinya. Sengaja membiarkan ayah tidak pulang lagi ke rumah. Ketika kutanya perihal Ayah yang menghilang, nenek hanya menjawab jika ayah dibawa peri terbang ke langit" (SP, hal. 52)

Juga pada kutipan ketika nenek menyuruh "Bunda" menghajar wanita selingkuhan suaminya, 'Bunda' menolak dan mengatakan:

“... Mugkin Bunda bukan orang yang pantas dan belum melakukan yang terbaik sebagai seorang istri."(SP: 53) 
Tergambar dalam beberapa kutipan di atas, citra perempuan tradisional yang lembut, ikhlas, sabar, dan setia. Berbeda dalam hubungan masyarakat modern, mereka memiliki orientasi nilai budaya yang berarah pada kehidupan dalam peradaban masa kini, yang menggambarkan hubungan kekerabatan yang mulai renggang, pergaulan bebas, juga terjadi adanya perselingkuhan. Perhatikan beberapa kutipan berikut.

"Berhentilah bertanya, pacak-pacaklah kamu nak nyari duet di mano," kata Ibu saya yang kesehariannya tidak jelas. Kadang ia di rumah, di pasar, belanja, memasak, lalu ke pasar lagi, mencuci, lalu ... entahlah ....". (CN., hal. 94-95)

Tergambar hubungan antara ibu dan anak yang tidak harmonis. Selanjutnya, gambaran tentang adanya pergaulan bebas, dalam cerpen TPHMK, tentang hubungan Rid dan Marya.

"Seperti seharusnya, akhirnya Marya melakukan ritual mandi kasai. Ritual adat Lubuklinggau yang dilakukan dengan cara memandikan dua calon pengantin di sungai, lengkap dengan pakaian adat di tubuh mereka. Rid melihat air sungai yang melewati kedua tubuh calon pengantin itu seakan membawa bayangan hitam dari tubuh yang dilaluinya. Bayangan dosa-dosa ljal dan Marya...." (TPHMK, hal 78)

"Rid hanya melihat dari kejauhan acara ritual itu, beberapa kali pandangan Rid dan Marya bertabrakan di udara, dia hanya melempar senyum. Senyum yang hanya bisa ditafsirkan oleh hati mereka masing-masing ...." (TPHMK, hal 79)

Pada kutipan berikut adanya hubungan sosial mayarakat modern berupa perselingkuhan yang digambarkan oleh tokoh Fatma dalam cerpen CPSCN.

"Tarsin adalah alasan sesungguhnya Fatma untuk berkeras menginap di penginapan, selain alasan tak mau merepotkan keluarga Bik Wit yang ia jawabkan pada semua orang. Termasuk suaminya Jaudi." (SPSCN:50)

Ternyata pergeseran nilai-nilai budaya sudah mempengaruhi citra positif perempuan dalam budaya tradisional.

\section{Simpulan}

Berdasarkan hasil analisis dan pembahasan, dapat diambil kesimpulan bahwa pergeseran nilai-nilai budaya dalam masyarakat membawa dampak perubahan dan pergeseran nilai-nilai di masyarakat, bisa dari nilai yang kurang baik menjadi baik ataupun sebaliknya. Agar perubahan dan pergeseran ini berjalan baik, maka perlu pengawasan dari kita semua. Jangan sampai budaya luhur yang telah ada menjadi kabur dan tidak up to date dengan lingkungan 
kekinian. Salah satu bentuk pergeseran nilai akibat pergeseran budaya yang ditemukan dalam kumpulan cerpen JJM adalah pergeseran cara pandang dan citra perempuan.

Pandangan dunia perempuan yang dominan dalam kumpulan cerpen JJM adalah campuran dunia domestik dan publik, dunia domestik, dan dunia publik. Perbedaan pandangan dunia perempuan ini melahirkan dua pandangan citra perempuan, yaitu citra positif dan citra negatif. Pandangan citra positif perempuan meliputi: kemandirian, kelembutan, kesabaran, ketabahan, kekuatan, ketegran, dan tanggung jawab. Sedangkan pandangan citra negatif perempuan adalah sifat masa bodoh, mengabaikan kesetiaan, dan kurang bertanggung jawab.

\section{Daftar Pustaka}

Aminuddin. (2010). Sekitar Masalah Sastra Beberapa Prinsip dan Model Pengembangannya. Malang: YA3.

Badan Pengembangan dan Pembinaan Bahasa. (2017). Kamus Besar Bahasa Indonesia (KBBI): Kamus Versi Online/Daring (dalam Jaringan). Jakarta: Badan Pengembangan dan Pembinaan Bahasa, Kemdikbud (Pusat Bahasa) Diakses pada 20 September 2017. https://kbbi.web.id/malam

Endraswara, Suwardi. (2013). Metodologi Penelitian Sastra. Yogyakarta: CAPS (Center for Akademic Publishing Service).

Fayumi, Badariyah. (2001). Keadilan dan Kesetaraan Gender (Perspektif Islam). Jakarta: Tim Pemberdayaan Perempuan Bidang Agama Departemen Agama RI.

Goldman, Lizbeth. (2001). Literature and Gender. New York: The Open University.

Kosasih. (2012). Dasar-Dasar keterampilan Bersastra. Bandung: Yrama Widya.

Milles B, Matthew \& Huberman. (2007). Analisis Data Kualitatif: Buku Sumber Metode-Metode Baru. Jakarta: Universitas Indonesia Press.

Noermanzah, N. (2017). Plot in a Collection of Short Stories "Sakinah Bersamamu" Written by Asma Nadia with Feminimism Analysis. Humanus: Jurnal Ilmiah Humaniora, 16(1). https://doi.org/10.24036/jh.v16i1.7015 
Rose, La Mimi, dkk. (2016). Jeramba-Jeramba Malam: 10 Cerpen Terbaik Sayembara Menulis Cerpen Lokalitas Lubuklinggau. Lubuklinggau: Bennyinstitute.

Setiadi, Elly M., dkk. (2010). Ilmu Sosial dan Budaya Dasar. Jakarta: Kencana.

Sihaloholistick. (2014). Nilai Perempuan dalam Sastra. (Online) Jendela Sastra, Media Sastra Indonesia. Diakses 4 Februari 2017. http://www.jendelasastra.com/wawasan/artikel/nilai-perempuan-dalamsastra?page $=0 \% 2 \mathrm{C} 1$

Suaka, I Nyoman. (2014). Analisis Sastra: Teori dan Apresiasinya. Yogyakarta: Ombak.

Sugihastuti \& Suharto. (2015). Kritik Sastra Feminisme: Teori dan Aplikasinya. Yogyakarta: Pustaka Pelajar.

Wicaksono, Andri. (2014). Menulis Kreatif Sastra dan Beberapa Model Pembelajarannya. Yogyakarta: Garudhawaca.

Zuhdi. (2017). Kepunan: Suplemen Gizi Spiritual untuk Mengajarkan Nilai-nilai Akhlak dan Patriotisme Berbasis Kearifan Lokal. (Makalah) disajikan dalam Bedah Buku "Kepunan" Karya Benny Arnas, 3 Februari 2017. 